\title{
DISFRUTO EL PODER DE SER FELIZ: EXPERIENCIA EN PERSONAS QUE VIVEN CON VIH
}

\author{
Enjoy the power of being happy: experience \\ in people who live with hiv
}

\section{EPISTEMUS}

ISSN: 2007-8196 (electrónico)

ISSN: 2007-4530 (impresa)

Guadalupe Erendira Montoya Ramirez ${ }^{1}$

Mayra Itzel Huerta Baltazar ${ }^{2}$

Mónica Fulgencio Juárez ${ }^{3}$

Gloria Correa Vieyra 4

Roberto Martinez Arenas 5

Recibido: 16 de septiembre de 2016,

Aceptado: 19 de noviembre de 2016

Autor de Correspondencia:

M. E. Guadalupe Erendira Montoya Ramirez

Correo:gemr_08@hotmail.com.mx

\section{Resumen}

Las personas que viven con virus de inmunodeficiencia humana $(\mathrm{VIH})$ pueden presentar alteraciones biopsicosociales que generan infelicidad. La gaudibilidad (capacidad para ser feliz y disfrutar), puede favorecerse al crear nuevos patrones de conducta mental con la programación neurolingüística (PNL). El propósito fue: analizar la experiencia vivida en un taller de PNL para personas que viven con $\mathrm{VIH}$, a la luz del referente teórico de; Rogers. Estudio cualitativo con diseño fenomenológico, participaron 12 personas de la Asociación CONVIHVE A.C. Michoacán, en un taller de PNL conformado por ocho sesiones. Tratamiento de datos por análisis de contenido, emergieron cinco dimensiones dejando ver el poder de cambio que tienen dichas personas para disfrutar la vida, al generar emociones positivas que se anclaron al inconsciente. Conclusiones. La PNL como intervención de enfermería favorece la gaudibilidad de las personas que viven con $\mathrm{VIH}$.

Palabras clave: Programación Neurolingüística, Gaudibilidad, Personas que viven con $\mathrm{VIH}$, Enfermería.

\section{Abstract}

People living with human immunodeficiency virus (HIV) can present biopsychosocial alterations that generate unhappiness. Gaudiness (ability to be happy and enjoy) can be favored by creating new patterns of mental behavior with neurolinguistic programming (NLP). The purpose was to analyze the experience lived in an NLP workshop for people living with HIV, in the light of the theoretical reference of; Rogers. Qualitative study with phenomenological design, participated 12 people of the Association CONVIHVE A.C. Michoacán, in an NLP workshop with eight sessions. Treatment of data by content analysis, emerged five dimensions showing the power of change that these people have to enjoy life, by generating positive emotions that anchored to the unconscious. Conclusions. NLP as a nursing intervention favors the gaudibility of people living with HIV.

Keywords: Neuro-linguistic programming, Gaudibility, People living with HIV, Nursing.

1 Facultad de Enfermería de la Universidad Michoacana de San Nicolás de Hidalgo / Hospital General "Dr. Miguel Silva" de la Secretaría de Salud del Estado de Michoacán.

2,3,5 Facultad de Enfermería de la Universidad Michoacana de San Nicolás de Hidalgo. Morelia Michoacán, México 4 Facultad de Enfermería de la Universidad Michoacana de San Nicolás de Hidalgo / Hospital Oncológico de Morelia de la Secretaría de Salud del Estado de Michoacán, México. 


\section{INTRODUCCIÓN}

Según lo mencionado en el informe del Programa Conjunto de Naciones Unidas sobre el $\mathrm{VIH} / \mathrm{sida}$ (ONUSIDA) en el marco del día mundial del Síndrome de Inmunodeficiencia Adquirida (sida), en 2014, 36.9 millones de personas en el mundo vivían con Virus de Inmunodeficiencia Humana (VIH), 1.2 millones de personas murieron de enfermedades relacionadas con el sida [1]. En México en diciembre del 2014, 190 mil personas vivían con $\mathrm{VIH}$, en el 2013; 4,965 personas murieron a causa de enfermedades asociadas al sida [2]. En Michoacán, las estadísticas del $\mathrm{VIH}$-sida se han mantenido estables al hacer un recuento de 1985 a septiembre de 2015 se contabilizan 5 mil 444 enfermos con VIH en la entidad, el mayor número de pacientes con este padecimiento se ubican en la capital del Estado, Morelia [3].

EI VIH ataca las células CD4 (cúmulo de diferenciación 4 o cluster of cuadruple diferentiation, en inglés) del sistema inmune, ocasionando que el organismo tenga mayor riesgo de contraer enfermedades más graves, como infecciones. La primera implicación en la persona que vive con VIH es el impacto emocional al saberse portador del virus y sentir una profunda angustia de darse cuenta que su vida ya no volverá a ser igual, teniendo entonces un alto riesgo de entrar en estado de depresión por miedo a la muerte inminente, que puede repercutir también a la familia directa.

En este sentido el impacto emocional de saberse con $\mathrm{VIH}$, suele ser negativo, caracterizado por tristeza, temor y ansiedad, disminuye a la vez las emociones positivas como optimismo, confianza, amor y esperanza. Cantú y Álvarez [4], mencionan que puede llegar a amenazar la vida, el bienestar físico y disminuir la autoestima, en donde la depresión en personas que viven con $\mathrm{VIH}$ se asocia especialmente a las pérdidas inmediatas y potenciales en cuanto a calidad de vida, sumadas al estigma que recae sobre ellas.

Padrós (2011) señala que las habilidades, creencias, estilos cognitivos y estilos de vida, vislumbran, en el sentido del humor, la capacidad de concentración, la amplitud de intereses, la capacidad para plantearse retos, la confianza en sí mismo y otras características que hacen que una persona disfrute más que otras en las mismas situaciones [5]. Las actividades placenteras han sido identificadas como una de las rutas de acceso al bienestar y dado que la gaudibilidad hace referencia a los moduladores que regulan el disfrute, si una persona tiene elevados niveles de gaudibilidad ello lo predispone a disfrutar frecuentemente con alta intensidad

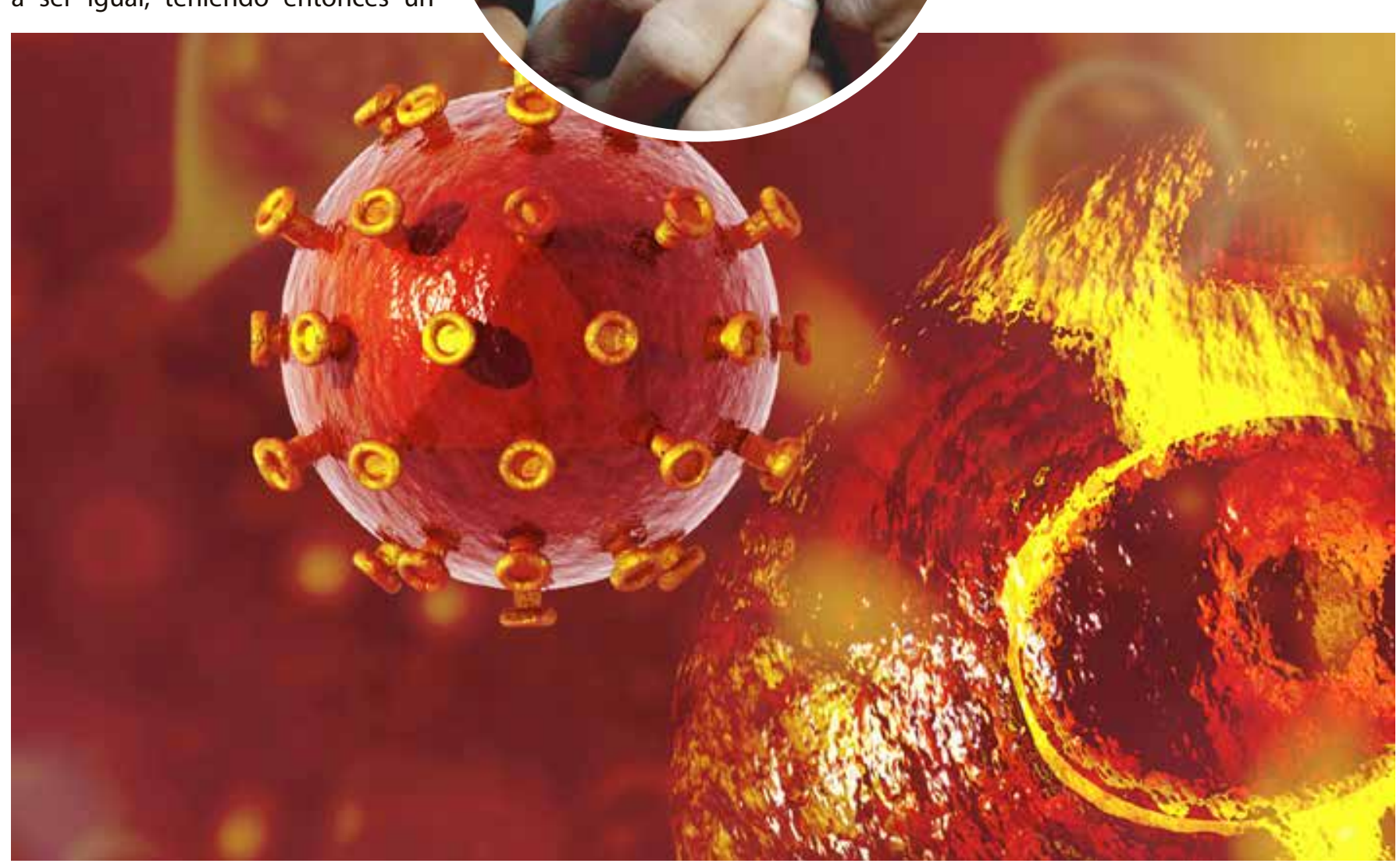




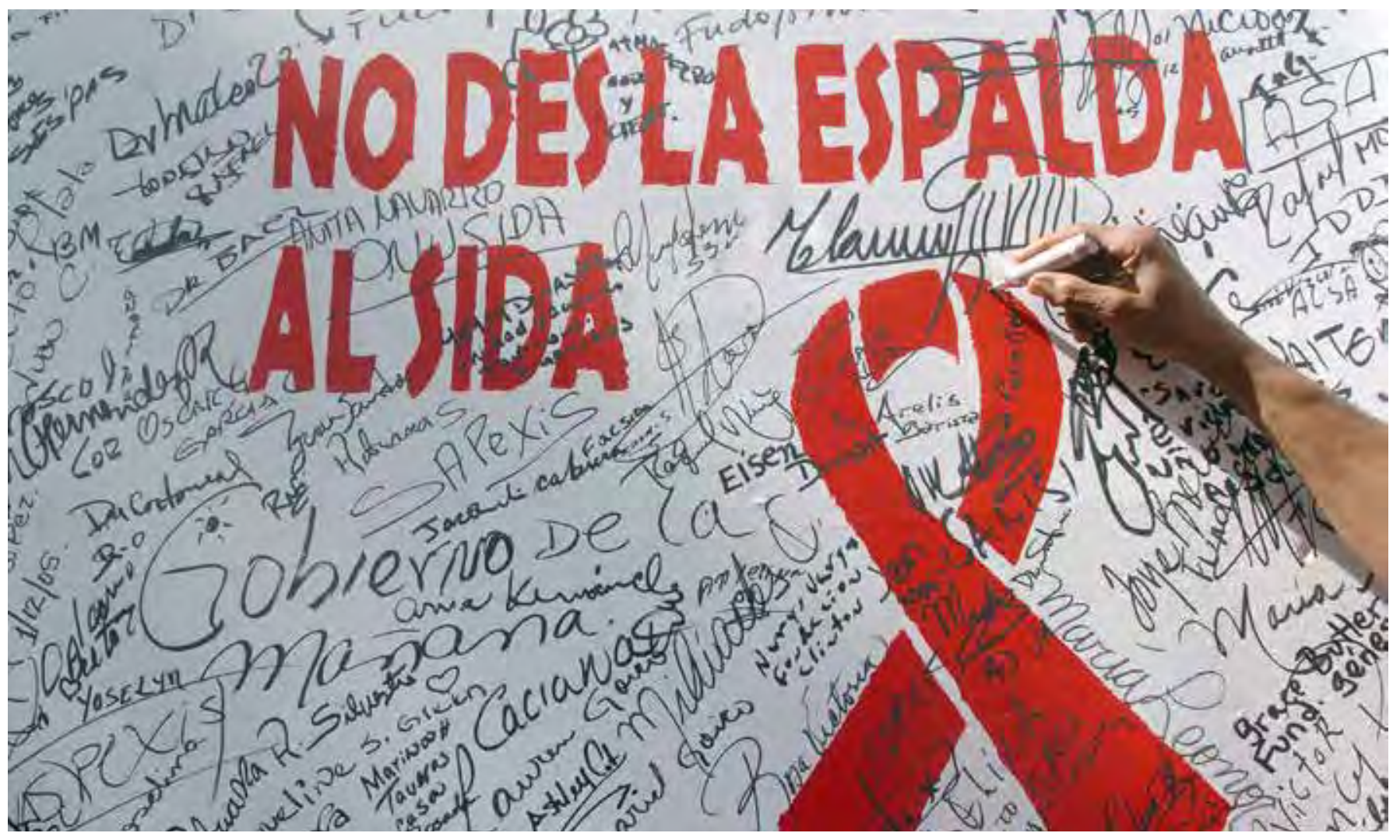

y frente a una gran cantidad de circunstancias que generan felicidad a la persona [6].

De tal modo que, si se aumenta el nivel de gaudibilidad, se aumenta el nivel de disfrute y con ello el nivel de afecto positivo y bienestar subjetivo [7], situación que se adapta a las personas que viven con $\mathrm{VIH}$, pudiéndose lograr a partir del uso de herramientas psicoeducativas orientadas a reprogramar a la persona para reparar el daño y la prevención de la enfermedad mental.

Este trabajo tuvo como referente teórico a Martha Elizabeth Rogers, quien afirma que, los seres humanos son campos de energía dinámicos, integrados en los campos del entorno. Ambos tipos de campos, obedecen a un patrón y se distinguen por su condición de sistemas abiertos [8], El objetivo de Enfermería según Martha Elizabeth Rogers es fomentar y promover la salud y el bienestar, buscando el balance y armonía entre el hombre y su entorno, con la PNL como actividad de Enfermería se cumple el objetivo de Martha Elizabeth Rogers de favorecer la creatividad de enfermería en el cuidado.

Así mismo los conceptos de la PNL que es el estudio de la experiencia humana subjetiva, cómo se organiza lo que percibe y cómo revisa y filtra el mundo exterior mediante los sentidos [9]. El profesional de la enfermería utiliza intervenciones actualizadas, probadas por la investigación y apoyadas por principios científicos, que le permiten actuar de manera independiente para fomentar la salud de la persona con el uso de herramientas alternativas, recordando que el ser humano es un sistema abierto.
$Y$ el concepto de gaudibilidad definido como: "El conjunto de moduladores que regulan el disfrute que las personas experimentan, lo cual repercute en el bienestar y la calidad de vida de las personas" [10]. Dado que la gaudibilidad hace referencia a los moduladores que regulan el disfrute, si una persona tiene elevados niveles de gaudibilidad ello lo predispone a disfrutar frecuentemente, con alta intensidad y frente a una gran cantidad de circunstancias que generan felicidad y salud a la persona [11].

Por lo anterior el propósito fue analizar la experiencia vivida en un taller de PNL para favorecer la gaudibilidad de PVVIH.

\section{MÉTODO}

Se trata de un estudio cualitativo con diseño fenomenológico. El universo de trabajo fue la Asociación CONVIHVE A.C. de Michoacán, México. Se contó la participación de 12 personas en edad productiva, siendo solo una mujer y once hombres. La Intervención fue un taller de PNL de ocho sesiones cada una de tres horas.

En la primera sesión se trabajó la habilidad para cambiar de estado emocional con el establecimiento de anclas, en la segunda sesión se reafirma la capacidad de tener cada día más emociones positivas y de mayor intensidad, en la tercera sesión se enseñó a direccionar la mente en busca de nuevas y benéficas soluciones, en la cuarta sesión se trabajó para cambiar pensamientos negativos por pensamientos positivos, en la quinta sesión se reafirma 


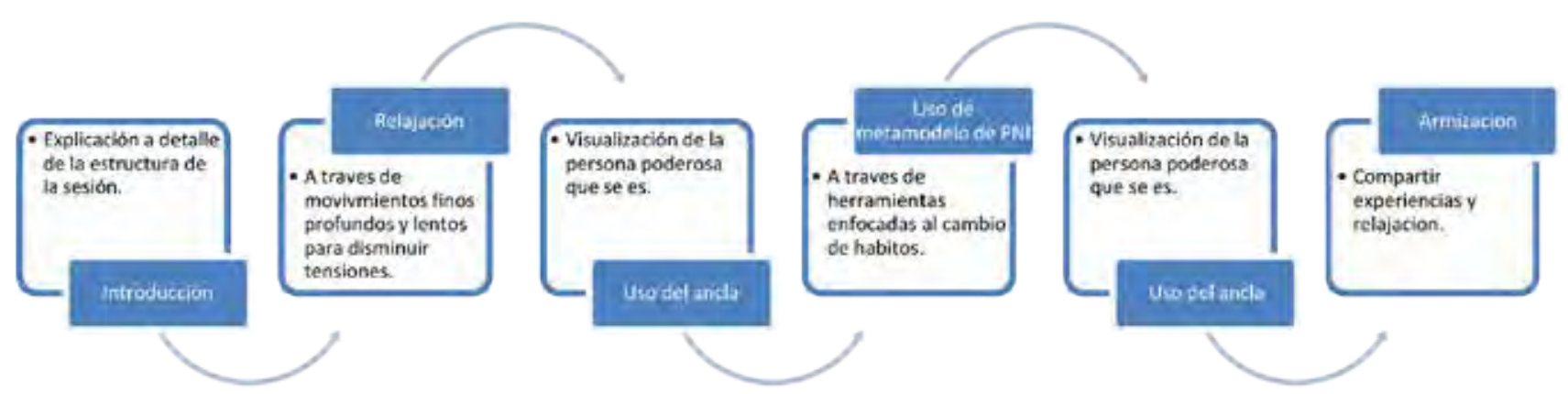

Figura 1. Metodología del taller de PNL, para personas que viven con VIH.

la capacidad para cambiar estados negativos, en la sexta sesión se trabajó en sentir y vivir la felicidad, en la séptima sesión se enseñó a entrar a un estado neutro y en la octava sesión se reafirman todas las herramientas aprendidas para crear un estado de poder, risa, paz y flexibilidad. Todas las sesiones siguieron la misma metodología para cumplir con una de las premisas de la PNL que es el crear nuevos hábitos, misma que se describe en la figura 1.

La recolección de datos se realizó a través de las técnicas de; buzón que es, un receptáculo que contiene una apertura adaptada para recolectar papeletas, el objetivo de esta técnica es recabar, por escrito, la experiencia vivida por los participantes. Y la técnica de observación participante que es, la descripción de los seres vivos en su medio natural que, requiere la implicación del investigador en el campo cultural ajeno de trabajo, a través de una inmersión completa a fin de conocer la vida real del grupo, modos de vida, etcétera [12], el tratamiento de los datos fue a través del análisis de contenido.

Para respetar el anonimato de los participantes se les otorgó un seudónimo con nombres de aves a cada uno, donde para asegurar la transparencia de esta investigación se consideraron las leyes, normas y códigos vigentes. Cuidando los principios éticos se informó al participante la naturaleza, duración y propósito del estudio, entregándosele el consentimiento informado donde emitió la aceptación a participar.

\section{RESULTADOS}

A la luz de los códigos vivos y como resultados emergen cinco dimensiones mismas que a continuación se describen:

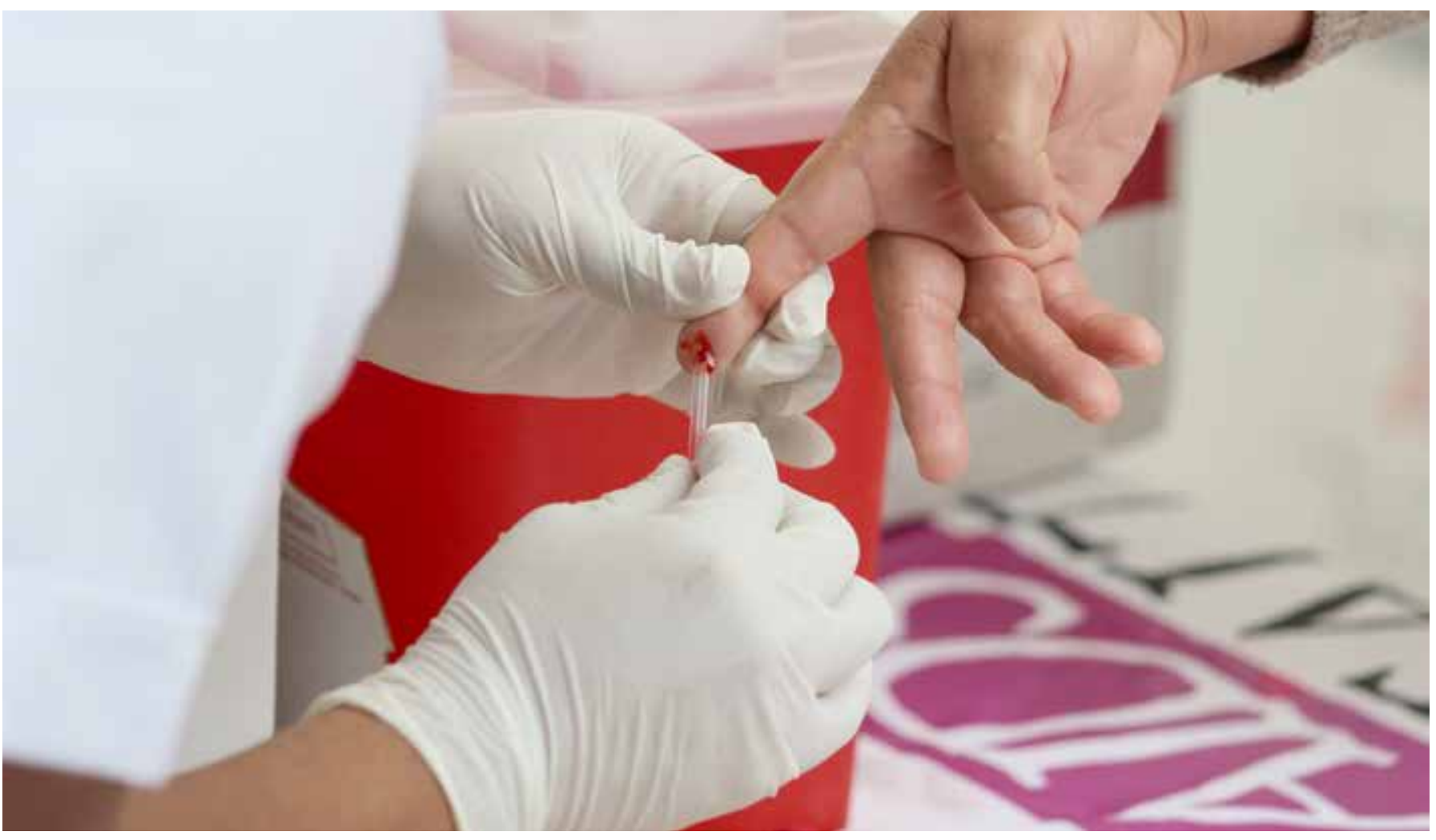




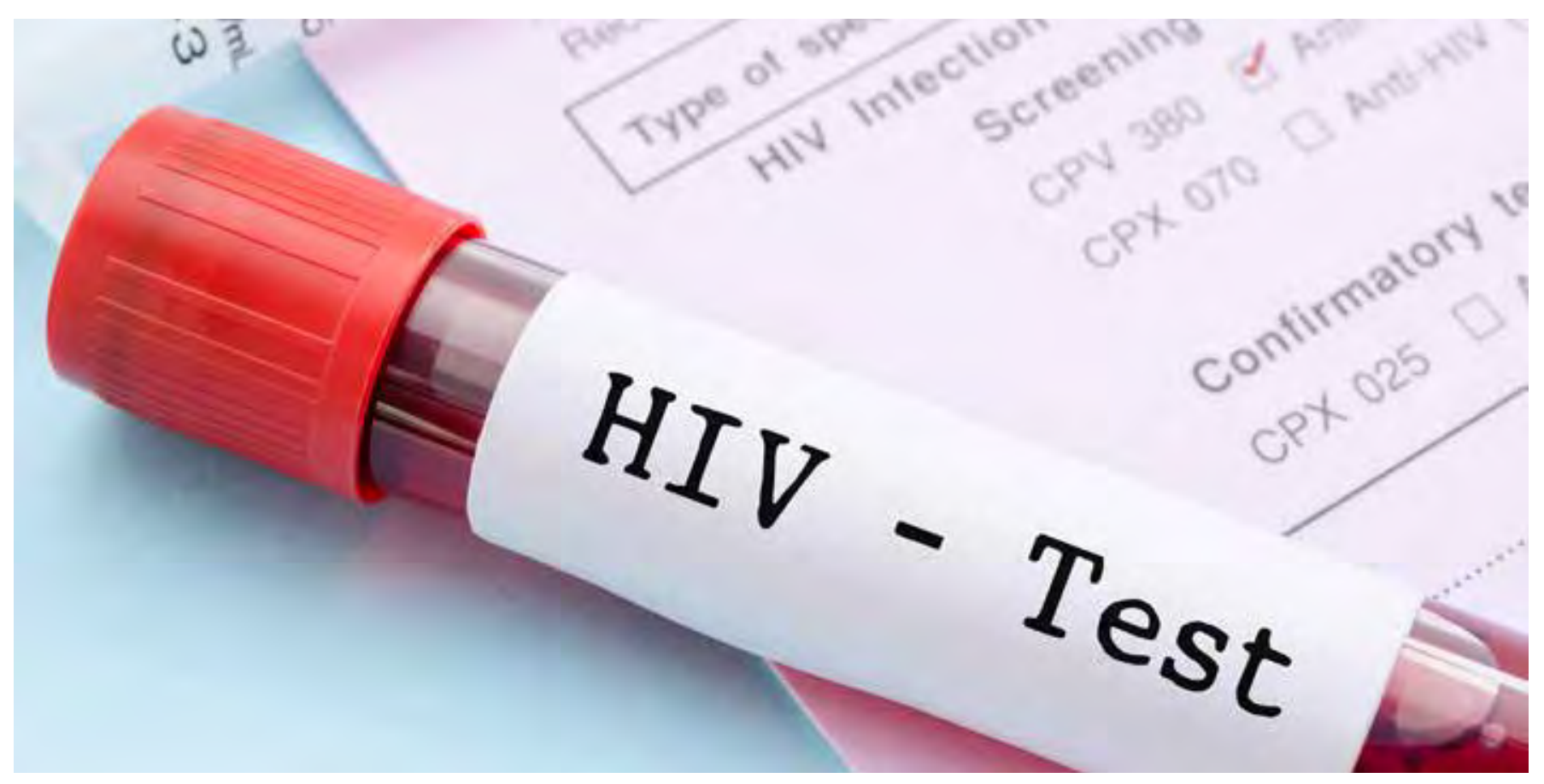

Dimensión: Extraordinariamente feliz, utilizar pensamientos y emociones positivas, vivir emociones satisfactorias, de disfrute que llevo al participante a sentir que soy especial, donde el inconsciente se apodera de esa sensación placentera y busca más. Al respecto los participantes expresaron: logré sustituir una emoción desagradable por una sensación de tranquilidad y de paz (Gorrión), donde las emociones de disfrute se hicieron presentes: me encanta el vaivén de emociones (Cetia), siendo consiente del poder que posee para decidir el tipo de emociones prevalezcan en el: es posible cambiar de estado de ánimo, todo depende de uno mismo (Águila).

Dimensión empoderamiento-sintiéndome yo: EI participante es consciente de los estados de disfrute que puede llegar a tener: darme cuenta de que soy la mejor (Águila); le recordó esa parte que quizá su inconsciente guardó: creo que tenía tiempo sin sentirme tan emocionado, sintiéndome yo (Bengalía); reactivó un estado poderoso que él poseía ya: que agradable volver a sentirme empoderado y con confianza (Colibrí). Dichas experiencias logradas través de las herramientas de la PNL se cumple una de las premisas que sostiene que, una vez que tu inconsciente se encuentra en la sima difícilmente querrá bajar: quiero seguir así de feliz siempre (Calandria).

Dimensión: camino a la plenitud la mejor versión de mí, al darse cuenta del poder interno que posee para cambiar sensaciones de malestar por sensaciones de bienestar el participante expresó: poder descubrir que mis enojos los puedo hacer a un lado y ser más tolerante y más feliz (Fénix), lo llevo a ser consiente del poder de cambio: me siento muy bien, siento que todo lo puedo (Cetia), logrando así re direccionar la mente para crear nuevos hábitos que le permitan ser una la mejor versión de él: me siento a gusto por sacar todo lo malo, me ayuda a ser mejor persona (Colibrí).

Dimensión: nuevo amanecer, trabajar intensamente para generar cambios necesarios en su vida, le permitió al participante anclar nuevos hábitos al inconsciente creando reacciones que le ayudan a renovarse. Al respecto los participantes expresaron: reinterpreto mi vida (Cetia), donde la experiencia de placer se hizo presente: hoy fue diferente, desperté mi mente, estuve flotando en el mar (Gorrión); explotando las capacidades de disfrute que posee: me gusto que ya no me costó trabajo concentrarme (Gavilán).

Dimensión: me amo y me apruebo; la felicidad se alcanza cuando la persona descubre los mejores recursos que tiene, y que los puede utilizar en el momento y en el contexto que lo desee, tal como lo expresaron los participantes: estoy seguro que lo lograré, tengo todo para ser feliz (Calandria). Con la ayuda de la PNL se logra vencer los miedos que limitan el disfrute y la plenitud personal que pudieran afectar la felicidad, como lo expresó Bengalia: Vencer mis miedos para emprender nuevos retos con alegría y 
optimismo estoy seguro que lo lograre, lo que llevó al participante a generar emociones de gran intensidad: siento en mi pecho una emoción que me fortalece y me anima a vencer mis miedos (Fénix) haciéndolo consciente del poder de disfrute que posee: sentí todo mi cuerpo y mi corazón como latía en mi ser (Gavilán).

\section{DISCUSIÓN}

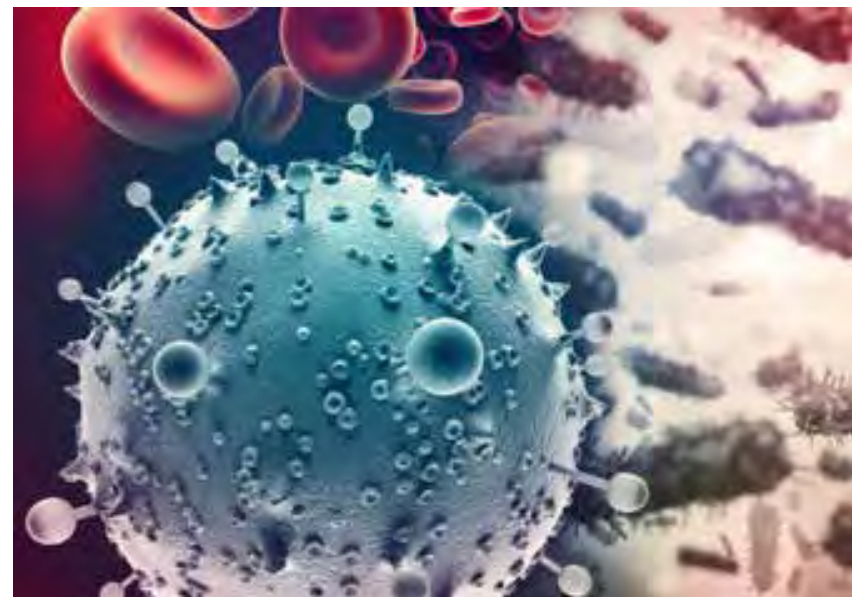

a sí mismo, se crearon nuevos hábitos para orientar sus acciones o pensamientos a la generación de placer, donde día a día creció la habilidad de los participantes para permanecer en un estado de mayor bienestar, evidencia que no fue posible compararla con otras investigadores, ya que no se encontró estudios que abordaran estos aspectos, por lo tanto, se ha generado un nuevo conocimiento que fortalecerá a las personas que viven con $\mathrm{VIH}$ y a las intervenciones de enfermería.

En esta investigación el participante se hizo consciente del poder de cambio que tiene para disfrutar de la vida, con el uso de los recursos que fueron adquiridos durante el taller de PNL, se reactivaron emociones placenteras que los condujeron a la felicidad; en torno a esto, Vázquez (2013) en su investigación titulada "La Felicidad y la Percepción de la Salud", comenta que los problemas de tipo psicológico están mucho más relacionados con la infelicidad que los problemas físicos [13].

Las intervenciones de enfermería despertaron en los participantes la tendencia natural de la mente que es pensar y la tendencia natural del cuerpo que es sanarse
Se ratifica uno de los postulados de Martha Elizabeth Rogers (2011) que dice; "La salud dependerá de las circunstancias y experiencias a lo largo de la vida de cada ser humano y la capacidad de este para lidiar y alcanzarla".

\section{CONCLUSIÓN}

Siguiendo el objetivo de enfermería de fomentar y promover la salud y el bienestar, buscando el balance y armonía entre el hombre y su entorno, la presente investigación se centró en la totalidad de la persona de modo humanístico, abstracto, juicioso y compasivo sin

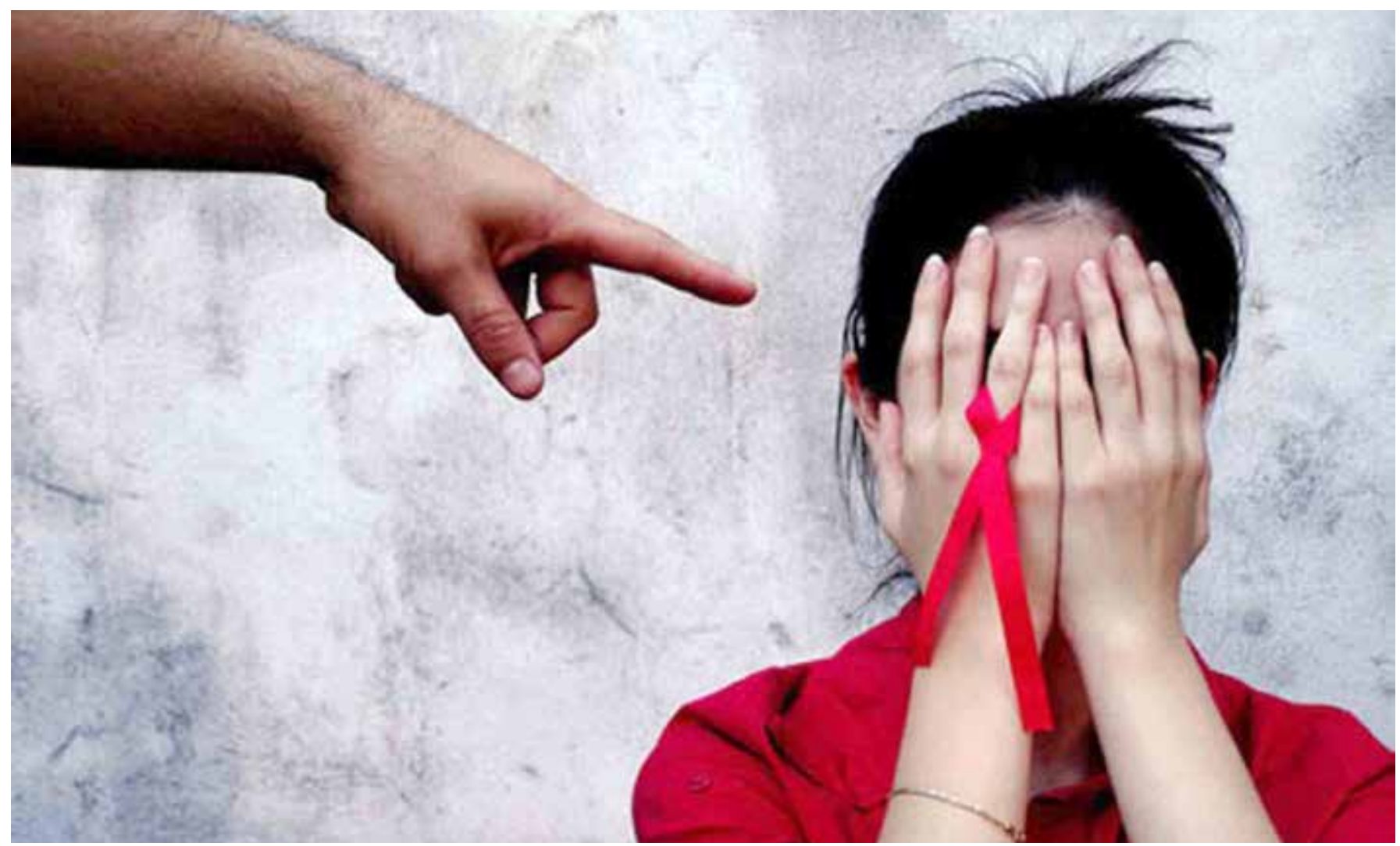




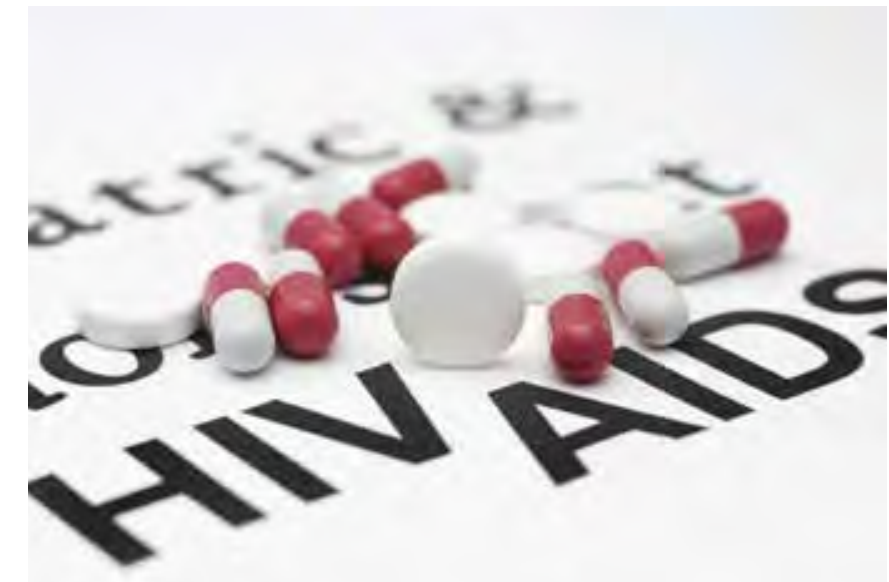

perder la creatividad y la inventiva en cada intervención, con la PNL como intervención de enfermería se cumple dicho objetivo, y con ello se contribuyó a la apertura de nuevos campos de acción para la enfermería, donde se favoreció la gaudibilidad de las personas que viven con $\mathrm{VIH}$, las cuales reavivaron emociones para el disfrute como; la risa, la paz, el poder interior y el bienestar. Estas, favorecieron el generar cambios positivos en los patrones de comportamiento, lo que determinó la efectiva de la PNL como intervención de enfermería por lo que se propone se promueva la utilización de esta en el cuidado de personas con otras condiciones crónico degenerativas, del mismo modo se recomienda continuar en la generación de evidencias que permitan sustentar esta intervención para ser incluida en la clasificación del NIC como intervención.

\section{BIBLIOGRAFÍA}

[1] Programa Conjunto de Naciones Unidas sobre el VIH/ SIDA (ONUSIDA), "El SIDA en cifras 2015". Día mundial del SIDA 2015. 20 Avenue Appia CH-1211 Ginebra 27 Suiza Accessed november 2015. [Online]. Available: http://www. unaids.org/sites/default/files/media_asset/AIDS_by_the_ numbers_2015_es.pdf

[2] Centro Nacional para la Prevención y Control del VIH/SIDA (CENSIDA), "Panorama de la respuesta nacional al VIH México 2015". $1^{\circ}$ de diciembre de 2015. Accessed december 2015. [Online]. Available: http://www.censida.salud.gob.mx/ descargas/diamundial/Panorama_nacional_de_la_respuesta_a_la_epidemia_de_VIH2015_1.pdf

[3] Secretaria de Salud de Michoacán (SSM), "Informe anual 2015" Departamento de Enfermedades de Transmisión Sexual y SIDA 2015. Accessed november 2015. [Online]. Available: http://www.moreliaymas.com/incrementancasos-de-vihsida-en-michoacan/

[4] R. Cantú and J. Álvarez, Impacto psicosocial en personas que viven con VIH-sida en Monterrey, México. Psicología y Salud, Vol. 22, Núm. 2: 163-172, julio-diciembre de 2012. Accessed may 2015. [Online]. Available: http://www.uv.mx/psicysalud/psicysalud-22-2/22-2/ Rodrigo\%20Cant\%FA\%20Guzm\%E1n_2.pdf

[5] F. Padrós, Nivel de Gaudibilidad en pacientes esquizofrénicos: un estudio piloto. Salud Ment vol.34 no.6 México nov./dic. 2011. Accessed May 2013. [Online]. Available: http://www.scielo.org.mx/scielo.php?script=sci_arttext\&pid=S0185-33252011000600007
[6] A. Castro, Las rutas del acceso al bienestar. Relaciones entre bienestar hedónico y eudaimónico. Un estudio en población argentina. Revista Iberoamericana de Diagnóstico y Evaluación Psicológica. 26(2), 117-139. 2011. Accessed May 2015. [Online]. Available: http:// alfama.sim.ucm.es/wwwisis2/wwwisis.exe/[in=psyke2.in ]/?format=breve\&boolean=\%5BNR:11353848

[7] F. Padrós, Disfruté y bienestar subjetivo. Un estudio psicométrico de la Gaudibilidad. Departamento de Psicología en Educación, Facultad en Psicología, Universidad de Barcelona 2012. Accessed may 2013. [Online]. Available: http://www.revistas.unc.edu.ar/index.php/revaluar/article/ download/.../448

[8] G. Anne, Fundamentos de Enfermería. 5ta ed. Barcelona: Editorial Diorki Servicios Integrales de edición, 2011. p. 98 Accessed April 2015. [Online]. Available: http:// enfermeriaactodecuidaryamar.blogspot.mx/2011/11/ martha-rogers-su-teoria-para-enfermeria.html

[9] L. Ferrari, El poder de tu mente. No te imaginas lo que tu mente puede hacer por ti. 2014. Tus buenos libros.com Accessed April 2016. [Online]. Available: http://www.tusbuenoslibros. com/resumenes/el_poder_de_tu_mente.pdf.

[10] F. Padrós and J. Fernández, Proposal to measure a modulator of the experience of enjoyment: The gaudiebility scale. Internacional J Psychology Psychological Therapy 2008;8(3):413-430. Accessed may 2013. [Online]. Available: http://www.ijpsy.com/volumen8/num3/214/a-proposal-tomeasure-a-modulator-of-the-EN.pdf

[11] F. Padrós, Gaudiebility Group Therapy in Depressed Patients: A Pilot Study. International Journal of Psychology and Psychological Therapy, 14, 1, 59-69, 2014 Printed in Spain. All rights reserved. 2014. Accessed february 2014. [Online]. Available: http://www.ijpsy.com/volumen14/num1/374/ gaudiebility-group-therapy-in-depressed-EN.pdf

[12] Q. Perea. Educación para la salud: (Reto de nuestro tiempo) Observación Participante. Ediciones Diaz De Santos, S.A. Doña Juana de Castilla, 22. 28027 Madrid España. ISBN: 847978-644-2. 2004.

[13] Vázquez C. 2013. La Felicidad y la Percepción de la Salud. Facultad de Psicología de la Universidad Complutense de Madrid. Millward Brown España. Accessed December 2014. [Online]. Available: https://es.scribd.com/ document/75236405/La-felicidad-y-la-percepcion-de-lasalud

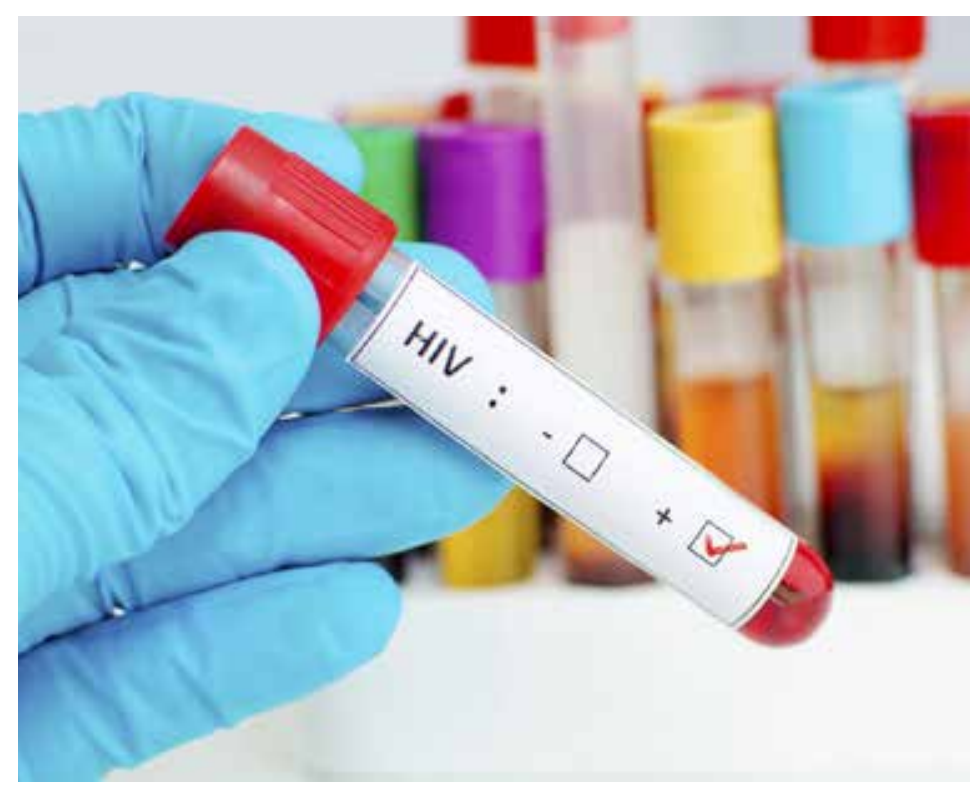

